\title{
Brand Flings: Emoções Passageiras com as Marcas ${ }^{1}$ Brand Flings: Passing Emotions With Brands Brand Flings: Emociones Pasajeras con las Marcas
}

\author{
Adriana Martins de Oliveira, Me. \\ Doutoranda pelo Programa de Pós-Graduação em \\ Administração - PUC/PR \\ Universidade do Estado do Rio Grande do Norte, Faculdade \\ de Ciências Econômicas. \\ Endereço: Av. Prof. Antônio Campos, Costa e Silva, CEP: \\ 59.625-620, Mossoró, RN - Brasil. \\ Telefone: (84) 33152202, e-mail: adrimartinso@gmail.com \\ Thaiseany de Freitas Rêgo, Me. \\ Doutoranda pelo Programa de Pós-Graduação em \\ Administração - PUC/PR \\ Endereço: Departamento de Agrotecnologia e Ciências \\ Sociais (DACS) \\ Av. Francisco Mota, 572 - Bairro Costa e Silva \\ Mossoró-RN I CEP: 59.625-900, e-mail: \\ thaiseany@ufersa.edu.br
}

\author{
Ana Maria Magalhães Correia, Me. \\ Universidade Federal Rural do Semi-Árido - UFERSA, \\ Departamento de Agrotecnologia e Ciências Sociais. \\ Endereço: Av. Francisco Mota, 572, Costa e Silva, 59625-900 - \\ Mossoro, RN - Brasil \\ Telefone: (84) 33178555, e-mail: \\ anamagalhaescorreia@gmail.com \\ Paulo de Paula Bapthista, Dr. \\ Professor do PPGA - PUC/PR \\ Endereço: Pontifícia Universidade Católica do Paraná, PPAD. \\ Imaculada Conceição, 1155, Prado Velho \\ 80215901 - Curitiba, PR - Brasil \\ Telefone: (41) 32711476 \\ Fax: (41) 32711476 \\ e-mail: p.baptista@pucpr.br
}

\section{RESUMO}

O objetivo do presente trabalho consiste em estudar o fenômeno brand flings como um tipo de relacionamento com as marcas. Para tanto, se utiliza de entrevistas semiestruturadas em profundidade, com oito potenciais usuários de marcas de itens do vestuário, perfumes e eletroeletrônicos. A seleção da amostra considerou indivíduos com formação acadêmica completa e estabilidade profissional. As entrevistas foram todas gravadas, com tempo médio de duração de 28 minutos, cujo processo de análise de conteúdo por meio do software Atlas.ti 5.0 se valeu da narrativa das experiências vivenciadas por cada um dos indivíduos com as marcas consumidas. $\mathrm{O}$ estudo aponta o brand flings como um tipo de relacionamento dos consumidores com as marcas, como tratado na teoria. Dentre os atributos encontrados para esse tipo de relacionamento, destaca-se o aspecto emocional do indivíduo, que se modifica de acordo com as fases específicas da vida. Observa-se ainda, tendências determinadas pela sociedade (moda) e o estabelecimento de ciclos de excitação (positivo) e tédio (negativo) com relação à marca. O brand flings também se volta a problemas gerados em razão de experiências ruins com as marcas, ocorridas em razão da qualidade, durabilidade, tamanho, aceitação de mercado (revenda) e prestação de serviços correlatos.

Palavras-chave: Relacionamento. Marcas. Brand flings.

\section{ABSTRACT}

The objective of this paper is to study the phenomenon brand flings as a kind of relationship with brands. Therefore, we used semi-structured in depth interviews with eight potential users of items of clothing brands, perfumes and electronics. The selection of the sample considered subjects with completes academic formation and professional stability. The interviews were engraved, with average duration of 28 minutes which process of content analysis by the software Atlas.ti 5.0 availed itself of the narrative of the experiences of each of the subjects with consumed brands. The study shows the brand flings as a kind of relationship of consumers with brands, as discussed in theory. Among the attributes found for this type of relationship, the

\footnotetext{
1 Artigo recebido em 29.11.2014. Revisado pelos pares em 15.01.2015 (blind review). Ajustado e Aceito para publicação em 01.03.2015. Recomendado para publicação por José Ribamar Marques de Carvalho (Editor Científico). Publicado em 01.04.2015. Organização responsável CCJS/UFCG.
} 
highlight is the emotional aspect of the individual, which changes according to specific stages of life. It was also observed, trends determined by society (fashion) and the setting of cycles of excitation (positive) and boredom (negative) with regard to the brand. The brand flings also is turned the problems generated due to bad experiences with brands that occurred on grounds of quality, durability, size, market acceptance (resale) and providing related services.

Keywords: Relationship. Brands. Brand flings

\section{RESUMEN}

El objetivo del presente trabajo es estudiar el fenómeno brand flings como un tipo de relación con las marcas. Para eso, se utilizó de entrevistas semiestructuradas en profundidad, con ocho usuarios potenciales de marcas de artículos de ropa, perfumes y electro-electrónicos. La selección de la muestra tomó en consideración individuos con formación académica completa y estabilidad laboral. Todas las entrevistas fueron grabadas, con tiempo medio de duración de 28 minutos, cuyo proceso de análisis de contenido a través del software Atlas.ti 5.0 se valió de la narrativa de las experiencias vividas por cada uno de los individuos con las marcas consumidas. El estudio indica que el brand flings es un tipo de relación de los consumidores con las marcas, como abordado en la teoría. De los atributos encontrados para este tipo de relación, se destaca el aspecto emocional del individuo, que se modifica de acuerdo con las fases específicas de la vida. Por otra parte, se ha observado tendencias dictadas por la sociedad (moda) y el establecimiento de ciclos de excitación (positivo) y tedio (negativo) con relación a la marca. El brand flings también se vuelve a problemas generados en razón de malas experiencias con las marcas, debido a la calidad, durabilidad, tamaño, aceptación de mercado (reventa) y prestación de servicios relacionados.

Palabras clave: Relación. Marcas. Brand flings.

\section{INTRODUÇÃO}

Relacionamentos são imprescindíveis na vida de todos, por contribuir para o desenvolvimento da existência das pessoas. A necessidade do relacionamento é natural e o ser humano não consegue viver isolado, uma vez que precisa conviver com outros para adicionar conteúdo à sua vida. Para Fournier (1998), assim como relações humanas são estabelecidas, os consumidores se relacionam com marcas de formas diversas.

A construção de um relacionamento com a marca é complexa, pois além de existirem numerosos tipos de relações, cada uma delas agrega emoções e normas distintivas. Embora o marketing possa estar interessado em desenvolver relações longas e duradouras com seus consumidores, nem todos os relacionamentos apresentam essas características (MACCINIS et al., 2009), uma vez que as pessoas os constroem, em parte, para criar uma autoimagem e apresentá-la aos outros ou para si mesmas (ESCALAS; BETTMAN, 2005).

Nesse contexto, as marcas ocupam atualmente um espaço de destaque, sendo consideradas sinônimo de competitividade e sobrevivência no mercado. Estão em todos os lugares e, por esse motivo, existe um grande esforço em pensar sobre como os relacionamentos com marcas são construídos, como evoluem e por que alguns deixam de existir. Esses estudos são decisivos para as teorias do marketing e, segundo Heding et al. (2009), a abordagem de relacionamento implica uma grande mudança no processo de gestão das marcas, podendo ser identificada como sinônima de gerenciamento da marca líder. Dessa forma, estudos sobre relacionamentos com marcas são de grande interesse para pesquisadores e profissionais de marketing.

Dentre os diversos tipos de relacionamentos com marcas identificados por Fournier (1998), brand flings é um tipo de relacionamento temporário, porém de alta 
recompensa emocional e sobre o qual pouco se sabe (ALVAREZ; FOURNIER, 2012). Esse relacionamento, de curto prazo e desprovido de compromisso, representa uma emoção para o novo, correspondendo a uma experiência agradável com a marca, na qual o consumidor dedica tempo e energia, embora, com o passar do tempo, o objeto perca o sentido e seja desprezado. Esse sentimento parece cada vez mais presente na sociedade contemporânea, cujos consumidores possuem um desejo insaciável e estabelecem relações efêmeras, de prazer passageiro.

Dessa forma, o propósito deste estudo consiste em explorar o fenômeno brand flings como um tipo de relacionamento dos consumidores com as marcas. O desafio é contribuir com a formação do corpo teórico desse construto e fomentar o desenvolvimento de conhecimentos nas áreas do marketing, gestão de marcas e comportamento do consumidor. Para atingir esse objetivo, o estudo fundamenta-se nas perspectivas de Fournier (1998) e Alvarez e Fournier (2012), apontando elementos sobre o relacionamento entre os consumidores e as marcas, e o tratamento do brand flings como um tipo de relacionamento com marcas.

Logo, são discutidos os aspectos metodológicos inerentes aos estudos exploratórios e à realização de entrevistas semiestruturadas em profundidade. Apresentam-se ainda os principais achados e discussões sobre o comportamento de consumo e o brand flings. Além disso, são levantadas algumas considerações sobre o relacionamento do tipo brand flings e, ainda, recomendações para pesquisas futuras.

\section{REVISÃO DA LITERATURA}

Aqui são discutidos os aspectos conceituais inerentes ao estabelecimento dos relacionamentos dos consumidores com as marcas. Destaque é dado à compreensão do brand flings como um tipo de relação efêmera de consumo. Esses pontos são abordados no sentido de subsidiar os questionamentos feitos aos entrevistados quanto ao seu respectivo relacionamento com as marcas.

\subsection{Relacionamento dos consumidores com as marcas}

A teoria do relacionamento ganhou destaque na área de gestão de marcas com o trabalho pioneiro de Fournier (1998), no qual a autora baseia-se na construção de metáforas concernentes a teoria das relações humanas, o abordando sob a perspectiva de um fenômeno interpessoal, construído entre os consumidores e suas marcas. A principal finalidade na construção desse relacionamento consiste na contribuição que a marca pode trazer para o consumidor, podendo levá-lo a desenvolver ou comunicar algo sobre si, e ajudando-o a atingir metas pessoais.

De acordo com a perspectiva do relacionamento, a imagem da marca corresponde a como o consumidor percebe a marca, bem como os significados transmitidos para o consumidor (AGARWALL, 2004). Nesse contexto, o consumo de uma determinada marca tem o propósito de dar sentido à vida das pessoas, assim como criar a identidade pessoal destas (McCRACKEN, 1989), sendo o mesmo 
compreendido por meio de uma analogia à complexidade cognitiva, afetiva e comportamental, que forma e transpassa os relacionamentos (BLACKSTON, 2000).

Trata-se, portanto, de uma abordagem centrada no intercâmbio entre a marca e o consumidor, uma relação díade, que é influenciada por diversos fatores contextuais (HEDING et al., 2009), em que as marcas possuem significados que vão além das suas características funcionais. Para Aaker et al. (2004), são as características de personalidade da marca que influenciam na qualidade desses relacionamentos. Porém, para que esses relacionamentos se estabeleçam, a marca precisa ser antropormofizada ou humanizada (FOURNIER, 1998), ou seja, qualidades humanas e personalidades precisam ser projetadas para as marcas.

Fournier (1998) identificou sete dimensões como categorias emergentes do relacionamento dos consumidores com as marcas, quais sejam: voluntária versus imposta, positivo versus negativo, intenso versus superficial, duradouro versus curto prazo, público versus privado, formal versus informal e simétrico versus assimétrico. A partir de uma análise conjunta dessas dimensões, quinze formas de relacionamentos foram identificadas: casamentos arranjados, amigos/companheiros casuais, casamentos por conveniência, parcerias comprometidas, melhores amigos, amizades compartilhadas, afinidades, recuperação/relacionamento orientado para a evasão, amizades de infância, namoros, dependências, flings, inimizades, assuntos secretos e escravidão. Após uma década dessa proposta conceitual, a autora conseguiu identificar cinquenta e duas dimensões de relacionamento, mostrando a diversidade dessa abordagem, apesar das mesmas limitarem-se apenas à exposição de algumas formas (ALVAREZ; FOURNIER, 2012).

A força do relacionamento é determinante para a estabilidade da relação, uma vez que atua diante da duração dos laços que o consumidor estabelece com a marca. A força desses relacionamentos foi discutida por meio do modelo conceitual de Brand Relationship Quality (BRQ), que evidenciou três tipos de ligações: ligações afetivas e socioemotivas, ligações comportamentais e ligações cognitivas. A proposta do modelo consiste em analisar o tipo de relação que os consumidores estabelecem com as marcas (FOURNIER, 1998).

Fournier (2009), ao seguir com seus refinamentos teóricos, destaca que, embora o BRQ tenha sido destinada a informar sobre questões complexas de relacionamento, esse modelo sofre um preconceito que restringe sua aplicação e seu alcance. Isso ocorre em razão das experiências que detém quanto à sensibilidade das métricas ao tipo de relacionamento, ou seja, não se pode medir a força ou a sua vitalidade de forma independente. A partir desse posicionamento, percebe-se a necessidade de se pesquisarem relacionamentos específicos, que evidenciem suas formas de medida particular. Na literatura, há diversos estudos que abordam o BRQ em diferentes contextos (GIFFORD JR., 1997; PARK et al., 2002).

Cabe destacar que muitos estudos sobre relacionamentos com marcas estão sendo desenvolvidos com a finalidade de compreender os aspectos emocionais 
dessas relações, assim como ocorre com as teorias de relacionamentos interpessoais. O trabalho desenvolvido por Thomson et al. (2005) sugere que os consumidores podem tornar-se emocionalmente ligados a objetos de consumo, incluindo as marcas como base para as diversas referências utilizadas. A pesquisa de Sternberg (1986) aponta que a teoria triangular do amor no campo interpessoal se utiliza de três componentes para explicar a natureza do amor: a intimidade, a paixão e o compromisso. Similarmente, Thomson et al. (2005) discutem uma medida que reflete a força dos laços emocionais estabelecidos entre as marcas e os consumidores, por meio de três fatores: afeto, paixão e conexão. Com isso, observa-se que a maioria dos estudos aceita que os consumidores desejam as marcas por motivos que vão além do seu despenho funcional, com destaque para o valor emocional que elas oferecem. Apesar das semelhanças apontadas na literatura entre relacionamentos interpessoais e de marca-consumidor, Swaminathan e Dommer (2012) identificaram algumas diferenças entre esses relacionamentos, o que limita a aplicação da metáfora.

Apesar de todos os efeitos psicológicos positivos que as marcas podem proporcionar para os consumidores, Fournier e Alvarez (2013) chamam a atenção para os relacionamentos negativos. Os autores comentam que, no meio acadêmico, há poucas pesquisas dedicadas a essa faceta do relacionamento, o que deturpa a realidade vivida nas interações das marcas com os consumidores. As relações negativas são significativas à medida que afetam não só os atributos do relacionamento com a marca, mas também a qualidade de vida do consumidor. Miller et al. (2012), ao investigarem oito tipos de relacionamentos, evidenciam que uma determinada marca pode servir como parceira de diversos tipos de envolvimentos. Marcas como a Apple ${ }^{\circledR}$, Starbucks $^{\circledR}$, Coca-Cola $^{\circledR}$ e Microsoft ${ }^{\circledR}$ podem gerar parceiras em um relacionamento sério, para uma pessoa, e objeto de uma relação conflituosa para outras, ou seja, podem causar efeitos positivos ou negativos.

Outro aspecto abordado por Fournier $(1998,2009)$ diz respeito à duração do relacionamento. Foram identificados relacionamentos com características de longo e curto prazo. Destaca-se que os relacionamentos de curto prazo, apesar de temporários, podem ter um alto envolvimento emocional. Nessas relações curtas, a marca torna-se o foco do consumidor por um período não duradouro, o que foi denominado pela autora como uma relação brand flings.

\subsection{Brand flings}

O consumo é um processo que vai muito além do momento em que uma pessoa decide se apropriar de um objeto. A correlação entre emoção e consumo é perceptível, uma vez que o consumo desperta emoções nos consumidores. Por esse motivo, o consumo nem sempre é uma atividade racional e envolve uma série de sinais e significados, ao invés de simplesmente um acúmulo de informações. É também uma combinação de sentimentos sobre si mesmo e com relação aos outros, além de desejos infinitos de origem duvidosa. 
De forma geral, destaca-se que os sentimentos permeiam as relações de consumo, fazendo com que surjam alterações ou se sustente uma determinada relação social. Isso ocorre, principalmente, em razão do simbolismo gerado pelo possuir e do significado estabelecido para a interação social. O consumo é não apenas afetivo, mas também desperta uma sensação de posse, que geralmente leva a pessoa ao pensamento de que tem poder sobre tudo o que possui, podendo vir acompanhado da sensação de ser alguém. A relação entre o consumo e emoção é tão íntima que o primeiro está, pouco a pouco, assumindo as características do último, ou seja, o caráter de uma prática que é fundamental para a constituição do self (GILJUÁREZ, 2009). O estudo de Illouz (2009) mostra que a emoção tem muito a contribuir para a sociologia do consumo, especialmente quando o mesmo é concebido como inerente ao processo de construção e manutenção da identidade.

O trabalho de Bauman (2001) sobre consumo, versa a respeito da brevidade das relações na atual sociedade. Para o autor, poucos ou nenhum bem, duramente conquistados, tendem a manter o seu fascínio por muito tempo, pois tendem a ser superados. As práticas de compras acabam por considerar a forte influência emocional, o que concorre, em igualdade de condições, com a razão, o que revela a existência de relacionamentos intensos e de curta duração.

Relacionando as duas características apresentadas nesta seção, o alto envolvimento emocional e o relacionamento de curta duração, Fournier (1998) definiu o que vem a ser o tipo de relacionamento com marcas, denominado de brand flings. Para a autora, trata-se de um relacionamento de curto prazo, ou seja, um engajamento por tempo limitado, porém de alta recompensa emocional. $\mathrm{O}$ mesmo foi identificado pela autora quando, em sua pesquisa, analisou as características da consumidora Vicki. Essa consumidora tinha 23 anos no momento da pesquisa e encontrava-se no último ano do mestrado, estando em um processo de transição, entre a fase de uma criança dependente e a de uma adulta independente e autossustentável, o que permite o desenvolvimento de um estilo de relacionamento pós-moderno com as marcas.

Nesse contexto, o consumidor pós-moderno não possui um padrão de orientação e suas principais características voltam-se para a pluralidade, a multiplicidade, a mutabilidade e a efemeridade. Esse consumidor não busca apenas uma relação satisfatória em termos de custo-benefício, mas vislumbra o significado do consumo nas suas relações. É a busca de vários "eus", de acordo com a situação vivenciada (BROWN, 1993; SMITHEE, 1997; BAUMAN, 2001). O pós-modernismo incentiva a construção de identidades individualizadas, por meio de empréstimos de fragmentos ecléticos e disponíveis na cultura do consumo. As mulheres são treinadas para as mudanças, sendo encorajadas a desenvolverem asas e não raízes (FOURNIER, 1998). As características de brand flings em Vicki não foram detectadas apenas em itens como shampoos (eram sete tipos diferentes, usados de acordo com o 
humor da consumidora e com o tipo de pessoa que ela queria ser), mas também em condicionadores, roupas e outros produtos.

Apesar de ser um tipo de relacionamento comum, no contexto da sociedade contemporânea, a primeira pesquisa que trata especificamente sobre brand flings (aventuras com marcas) é um tipo de relacionamento recente (ALVAREZ; FOURNIER, 2010). O referido estudo foi desenvolvido em um ambiente universitário, contemplando discentes em processo formativo nos Estados Unidos. Nessa perspectiva, Alvarez e Fournier (2012) apontam o brand flings como um tipo válido de relacionamento com marcas e apresentam cinco características essenciais.

A primeira característica essencial, diz respeito a um tipo de relacionamento altamente emocional, no geral, com sentimentos positivos de prazer. Esse sentimento é evidente no estágio inicial do relacionamento, uma vez que considera a emoção para o novo. A segunda característica diz respeito à natureza das interações que, no geral, são intensas e podem ser até mesmo obsessivas. Já a terceira característica refere-se à superficialidade do processo de tomada de decisão, uma vez que esta geralmente não é tomada de forma racional. É a suspensão do pensamento analítico, em que impulsos e desejos comandam as ações dos consumidores. A quarta característica definidora de brand flings envolve a conexão entre o consumidor e a marca e o seu papel em uma auto-apresentação. Finalmente, a quinta característica diz respeito à transitoriedade. Apesar da mesma representar o final de um relacionamento, em brand flings, essa passagem pode não indicar um ponto final na relação. O consumidor pode continuar no relacionamento com uma determinada marca, embora a alta emotividade e o engajamento intenso desapareçam com o tempo. A relação continua, porém sem aquele fascínio inicial. Flings é caracterizado como um fenômeno transitório, mesmo quando duram meses.

A transitoriedade, em termos de brand flings, foi estudada na área da psicologia, considerando objetos transicionais e o comportamento das crianças (WINNICOTT, 1953) e é possível fazer uma analogia entre os temas. Nessa perspectiva, a maioria das crianças possui um objeto ao qual elas recorrem quando necessitam de algum consolo, representando, portanto, a primeira possessão. É a iniciação de uma forma afetuosa com um objeto e, a partir dessa realidade, o pensamento simbólico é construído. Para algumas crianças, esse objeto pode ser um brinquedo, um ursinho de pelúcia, um paninho, ou um travesseiro macio que, com o tempo, acaba sendo esquecido e, aos poucos, abandonado. A criança pode até não esquecer o objeto, mas não chora por ele. No contexto do relacionamento consumidor-marca, o mesmo pode acontecer.

Relacionamentos emocionais entre os consumidores e as marcas podem ser formados de diversas maneiras (AHLUWALIA; KAIKATI, 2010) e, no contexto de brand flings, os consumidores descobrem modos diversos de vivenciá-las. $\mathrm{Na}$ literatura, foram identificadas quatro variações de um relacionamento flings: a) como uma fase específica ou período na vida dos consumidores. Nessa situação, os 
consumidores sentem que a marca representa quem eles são, apesar de reconhecer que esse tipo de ligação é temporário. O período pode ser definido tanto pela idade, quanto por mudanças mais amplas na vida do consumidor e na necessidade de outros produtos; b) como uma tendência social relacionada a um modismo. Determinadas marcas podem alcançar popularidade e status rapidamente, tornandose atraente para os consumidores; c) como um ciclo rápido de excitação e tédio. Nesse caso, flings são caracterizadas por um período de intensa relação com a marca, sendo que esse relacionamento literalmente esgota o que a marca tem para oferecer; e d) como um caso de curto prazo, encerrado pela má experiência com a marca. Este tipo de brand flings é baseado no fracasso da marca para sustentar um relacionamento forte com o consumidor (ALVAREZ; FOURNIER, 2012).

Por meio da revisão da literatura sobre o assunto, verifica-se que os conceitos relacionados à brand flings ainda são embrionários, sendo necessário um maior número de pesquisas para que se possa compreender esse fenômeno como um tipo de relacionamento consumidor-marca, bem como suas repercussões no comportamento do consumidor e no contexto da gestão das marcas.

\section{PROCEDIMENTOS METODOLÓGICOS}

Considerando as discussões inerentes ao relacionamento dos indivíduos com a marca e a questão do brand flings (ALVAREZ; FOURNIER, 2012), procedeu-se com a realização de estudos exploratórios, do tipo multicaso. Esse método possibilita aproximar o pesquisador do ambiente que se deseja estudar, bem como realizar inferências teóricas a cada caso. Para Yin (2010), essa técnica auxilia o pesquisador a contornar os desafios inerentes às pesquisas na área das ciências sociais, bem como compreender os fatos.

Considerando os aspectos enumerados, o presente estudo configura-se como do tipo qualitativo. Segundo Martins e Theóphilo (2009, p. 61) prima pela “descrição, compreensão e interpretação de fatos e fenômenos". Essa técnica requer uma análise minuciosa do ambiente, aliando os dados obtidos com os aspetos conceituais inerentes ao brand flings.

O nível de apreciação do estudo é o indivíduo. A seleção da amostra encontrase subsidiada na observação prévia do processo de consumo de alguns indivíduos e suas respectivas relações com marcas, seguido da realização de uma entrevista semiestruturada em profundidade (HEDING et al., 2009). Com a observação, foram destacados oito indivíduos para fazer parte do estudo, quatro homens e quatro mulheres, que possuem formação acadêmica e estabilidade profissional.

A entrevista resgatou as discussões anunciadas no estudo de Alvarez e Fournier (2012), quanto ao relacionamento com marcas e o brand flings. Dentre os itens de consumo anunciados pelos participantes da pesquisa, destacam-se: vestuário, veículos, perfumes e eletroeletrônicos de uso individual. Atendendo as perspectivas de confiabilidade, requerida por Martins e Theóphilo (2009) e Yin 
(2010), as informações obtidas foram trianguladas, mediante a observação do indivíduo durante a entrevista.

As entrevistas foram todas registradas, conforme a ocasião e disponibilidade do equipamento eletrônico, com o Gravador Olympus $^{\circledR}$, $i P a d^{\circledR}$ ou Smartphone Samsung ${ }^{\circledR}$, mediante comunicação e autorização prévia do entrevistado. Esse cuidado se deu para evitar qualquer problema que pudesse constranger ou interromper o raciocínio do respondente (ROSA; ARNOLDI, 2006). Paralelamente, foi mantido um livro de registro, para descrição do ambiente onde cada entrevista foi realizada, bem como identificar se haviam marcas que estavam sendo utilizadas e não foram declaradas no momento da entrevista.

A análise dos dados partiu do método dedutivo de análise, embasado nos conceitos teóricos de Alvarez e Fournier (2012). Além disso, adotou-se a técnica de análise de conteúdo discutida por Bardin (1977), que trata sobre um conjunto de técnicas que permitem proceder com a análise de narrativas. Essa técnica de análise de dados foi escolhida em razão de permitir a descrição e desocultação de significados após codificações e categorizações de modo objetivo e sistemático (MACIEL et al., 2012). Essas narrativas totalizaram 3 horas, 42 minutos e 34 segundos. As mesmas foram transcritas com o intuito de permitir a análise dos diálogos, por meio da codificação e categorização das respostas, realizada mediante o auxílio do software Atlas.ti 5.0.

Os procedimentos para análise dos dados foram divididos nas seguintes etapas: (a) pré-análise em função do interesse do pesquisador em elaborar um plano geral de análise; (b) exploração do material necessário à execução dos procedimentos definidos na pré-análise; e (c) o tratamento dos resultados, mediante inferência e interpretação, de modo a permitir condensações em relação às informações extraídas na análise. Destaca-se que esses procedimentos ocorrem principalmente por meio da codificação das mensagens e enumeração ou decomposição das entrevistas em categorias de análise, como discutido no estudo de Maciel et al. (2012).

\section{DESCRIÇÃO E ANÁLISE DOS DADOS}

Em uma análise inicial, procedeu-se com a exploração do material coletado, por meio da utilização de elementos inerentes a estatística de frequência das palavras. As mesmas foram analisadas e agrupadas em grupos de palavras plenas (verbos, adjetivos e substantivos) e instrumento (pronomes, conjunções, advérbios), como pode ser observado na Tabela 1.

Tabela 1: Estatística das palavras da entrevista

\begin{tabular}{c|c|c}
\hline \multicolumn{1}{c|}{ TIPOS DE PALAVRAS } & N.o DE PALAVRAS & PERCENTUAL \\
\hline Palavras plenas & 1.526 & $88,98 \%$ \\
\hline Palavras instrumento & 189 & $11,02 \%$ \\
\hline TOTAL & $\mathbf{1 . 7 1 5}$ & $\mathbf{1 0 0 \%}$ \\
\hline
\end{tabular}

Fonte: Dados extraídos do Atlas.ti 5.0. 
A estatística de palavras obtida no corpus da análise, com o auxílio do Word Cruncher do Atlas.ti 5.0, possibilitou a identificação de 12.995 palavras nos diálogos desenvolvidos durante as nas entrevistas, das quais 1.715 são diferentes. Nessa perspectiva, destaca-se a adoção de $88,98 \%$ de palavras plenas, entre verbos (556), adjetivos (240) e substantivos (730). Considerando esses aspectos, observa-se a presença de 18 palavras plenas, utilizadas com maior frequência, como pode ser visualizado na Tabela 2.

Tabela 2: Frequência das palavras plenas mais citadas na entrevista

\begin{tabular}{c|c|c|c|c|c}
\hline PALAVRA & FREQUÊNCIA & PALAVRA & FREQUÊNCIA & PALAVRA & FREQUENCIA \\
\hline Marca & 157 & Ser & 58 & Compro & 36 \\
\hline Tem & 86 & Pode & 46 & Boa & 36 \\
\hline Marcas & 61 & Certo & 46 & Bolsa & 35 \\
\hline Foi & 60 & Experiência & 45 & Relação & 32 \\
\hline Comprar & 59 & Vou & 43 & Tempo & 29 \\
\hline Qualidade & 59 & Produto & 41 & Preço & 29
\end{tabular}

Fonte: Dados extraídos do Atlas.ti 5.0.

As palavras anunciadas na Tabela 2, juntas, foram pronunciadas 958 vezes durante a realização das entrevistas. Essa distribuição aponta a ocorrência de seis verbos (33\%), o que ilustra o direcionamento de ações voltadas à aquisição de produtos. A frequência na adoção das palavras "marca" e "marcas", revelam o quanto os indivíduos selecionados se mostram atentos à escolha e utilização de produtos de marca, tais como: Apple ${ }^{\circledR}$, Carmen Steffens $^{\circledR}$, Calvin Klein ${ }^{\circledR}$, Samsung ${ }^{\circledR}$, Zefirelli $^{\circledR}$, Sergio's ${ }^{\circledR}$, Abercrombie \& Fitch $^{\circledR}$. Destaca-se também, a frequência da palavra "relação", que evidencia o modo como os entrevistados estabelecem relacionamentos com as marcas anunciadas no discurso dos entrevistados.

As expressões "qualidade", "tempo" e "preço" também foram citadas de forma representativa, corroborando com os fatores que influenciam o processo de escolha de marca e aquisição de produtos de uso pessoal. O termo "experiência", que remete ao conhecimento de marca, também foi retratado pelos entrevistados como um elemento importante para definir os critérios de compra e recompra de um produto. No que diz respeito aos itens de consumo anunciados pelos respondentes, destaca-se a "bolsa", um dos acessórios femininos cuja escolha ocorre de acordo com o estilo, qualidade e durabilidade do produto.

Na sequência, realizou-se a codificação da entrevista com a finalidade de categorizar as falas dos respondentes de acordo com o que preceitua as orientações de Alvarez e Fournier (2012), quanto ao brand flings. A unidade de registro escolhida para o tratamento dos dados e atribuição dos códigos foram frases completas e partes de frases (MACIEL et al., 2012). A adoção dessa técnica foi possível com o auxílio do Atlas.ti 5.0, que permite memorizar os códigos atribuídos a entrevista e possibilita a 
sua aplicação as demais, mediante a opção Code by List. Destaca-se que o estudo resultou na atribuição de 92 códigos de análise de conteúdo, empregados em 758 citações ou trechos textuais (Quotations), o que representa um índice de 8,24 trechos de frases ou frases por código.

Para a agregação dos códigos e classificação das categorias, foi utilizado o procedimento dedutivo, cujas categorias são embasadas nas discussões teóricas de Alvarez e Fournier (2012), que aponta o caminho para a identificação de um conjunto de nós críticos relacionados ao brand flings. Os códigos foram, então, elencados em categorias ou famílias de códigos (Code Family), considerando as peculiaridades anunciadas pelos respondentes, quanto à decisão de escolha de um produto, como pode ser visualizado na Tabela 3.

Tabela 3: Distribuição dos códigos e citações por categoria

\begin{tabular}{|c|c|c|c|c|c|}
\hline FATOR & CATEGORIAS & N. ${ }^{\text {COD. }}$ & $\%$ COD. & N. CITA. & $\%$ CITA. \\
\hline \multirow{5}{*}{$\begin{array}{l}\text { Momento da } \\
\text { vida }\end{array}$} & Auto-apresentação & 5 & $5,5 \%$ & 37 & $4,9 \%$ \\
\hline & $\begin{array}{c}\text { Motivações pessoais de } \\
\text { mudança }\end{array}$ & 8 & $8,7 \%$ & 62 & $8,2 \%$ \\
\hline & $\begin{array}{c}\text { Relacionamento altamente } \\
\text { emocional }\end{array}$ & 1 & $1,1 \%$ & 2 & $0,3 \%$ \\
\hline & $\begin{array}{l}\text { Relação contínua sem } \\
\text { fascínio }\end{array}$ & 6 & $6,5 \%$ & 104 & $13,8 \%$ \\
\hline & $\begin{array}{l}\text { Superficialidade do processo } \\
\text { de tomada de decisão } \\
\text { (irracional) }\end{array}$ & 1 & $1,1 \%$ & 7 & $0,9 \%$ \\
\hline \multirow{3}{*}{ Moda } & Emoção para o novo & 4 & $4,3 \%$ & 17 & $2,3 \%$ \\
\hline & $\begin{array}{l}\text { Consumo comandado pelo } \\
\text { desejo }\end{array}$ & 3 & $3,3 \%$ & 48 & $6,4 \%$ \\
\hline & $\begin{array}{c}\text { Consumo comandado pelo } \\
\text { impulso }\end{array}$ & 2 & $2,2 \%$ & 13 & $1,7 \%$ \\
\hline $\begin{array}{l}\text { Motivação } \\
\text { passageira }\end{array}$ & $\begin{array}{l}\text { Transitoriedade no } \\
\text { relacionamento }\end{array}$ & 9 & $9,8 \%$ & 55 & $7,3 \%$ \\
\hline \multirow{10}{*}{$\begin{array}{l}\text { Experiência } \\
\text { vivenciada }\end{array}$} & Desencanto com a marca & 6 & $6,5 \%$ & 72 & $9,5 \%$ \\
\hline & Desencanto com o produto & 9 & $9,8 \%$ & 31 & $4,1 \%$ \\
\hline & Desencanto com o serviço & 5 & $5,4 \%$ & 12 & $1,6 \%$ \\
\hline & $\begin{array}{c}\text { Conexão entre o consumidor } \\
\text { e a marca }\end{array}$ & 9 & $9,8 \%$ & 111 & $14,7 \%$ \\
\hline & Interações intensas & 4 & $4,3 \%$ & 19 & $2,5 \%$ \\
\hline & Interações obsessivas & 1 & $1,1 \%$ & 15 & $2,0 \%$ \\
\hline & $\begin{array}{l}\text { Relacionamento de baixa } \\
\text { emotividade }\end{array}$ & 3 & $3,3 \%$ & 8 & $1,1 \%$ \\
\hline & $\begin{array}{l}\text { Relacionamento de baixa } \\
\text { intensidade }\end{array}$ & 4 & $4,3 \%$ & 10 & $1,3 \%$ \\
\hline & Sentimentos positivos & 8 & $8,7 \%$ & 74 & $9,8 \%$ \\
\hline & Ausência de brand flings & 4 & $4,3 \%$ & 61 & $8,1 \%$ \\
\hline & TOTAL & 92 & - & 758 & - \\
\hline
\end{tabular}


Fonte: Dados extraídos do Atlas.ti 5.0.

Com relação à quantidade de códigos por categoria, observou-se que a mesma variou de 1 a 9. No entanto, é importante salientar que alguns códigos foram usados em mais de uma categoria, em razão da mesma se adequar ao contexto estudado, estabelecendo um total de 92 códigos. Considerando os dados apresentados, o estudo confirma as características relacionadas à aventura com marcas, como apontado por Alvarez e Fournier (2012), dentre as quais se destacam o momento da vida, moda, motivação passageira e experiência vivenciada.

Nesse sentido, identificou-se que o fator relacionado à experiência vivenciada pelo consumidor, configura-se como um determinante para a aquisição de uma marca. Um ponto interessante que foi observado na análise das entrevistas, é que as experiências negativas (desencanto) com a marca, produto ou serviço, favorecem para que o consumidor estabeleça relacionamentos do tipo brand flings. O estudo aponta ainda, que os indivíduos assumem posturas distintas com relação à marca, dependendo do tipo de produto, fidelidade à marca e da função que cada um exerce em suas atividades diárias.

Com a identificação das famílias de códigos (categorias), iniciou-se o processo de articulação desses elementos para interpretação dos resultados. Nesse momento, adotaram-se técnicas de articulação entre as categorias criadas, de modo a permitir a visualização do mapa de redes estabelecido para a metapropriedade do brand flings vinculada em torno da categoria central na rede. As 19 categorias criadas foram analisadas com a identificação do mapa em rede, extraído por meio do Network View.

A interpretação dessas relações ocorreu a partir de quatro elementos: leitura do corpus textual da entrevista, conhecimento prévio das categorias, extraídas do referencial teórico, e visualização dos esquemas gráficos no Atlas.ti 5.0. Em seguida, todas as categorias foram relacionadas em uma rede, para representação gráfica das articulações entre as categorias existentes e seus respectivos Nodes, conforme Figura 1. Segundo Maciel et al. (2012), esses esquemas gráficos permitem visualizar os códigos estabelecidos e definir mais precisamente cada categoria, bem como identificar a relação existente entre as famílias de códigos. 


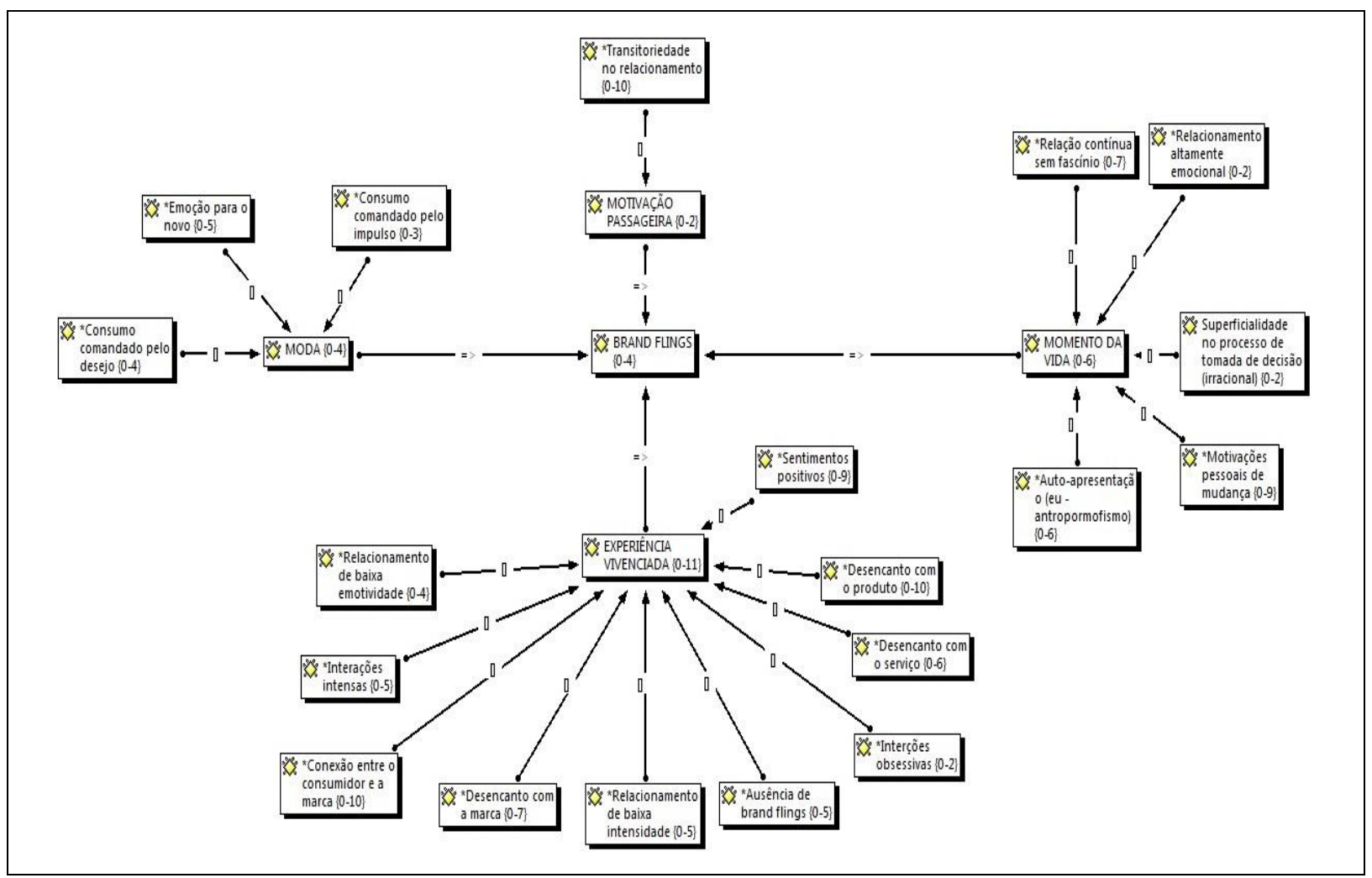

Figura 1: Relação entre categorias (Code Family) da rede

Fonte: Dados extraídos do Atlas.ti 5.0.

Com relação à rede exposta na Figura 1, verifica-se que a interpretação se dá em virtude da categoria central de análise, o brand flings, sinalizar o tipo de relacionamento existente e as variações de comportamento de consumo tratadas no estudo de Alvarez e Fournier (2012). Dentre os pontos que chamam mais atenção, destacam-se o alto nível emocional, as interações intensas e obsessivas com as marcas, bem como a superficialidade observada no processo de tomada de decisão de compra de produtos de marca. Além disso, constatou-se que o brand flings está inserido dentro de uma conexão entre o consumidor e a marca.

Considerando as relações estabelecidas quanto ao fator do "momento da vida", verifica-se que a mesma possui três Nodes vinculados a: relação contínua sem fascínio, relacionamento altamente emocional, superficialidade no processo de tomada de decisão (irracional), motivações pessoais de mudança e auto-apresentação (eu-antropomorfismo). Os respondentes revelam que seu comportamento se modifica de acordo com a fase vivenciada, bem como em relação à confiança na marca, influências de terceiros, necessidade de uso e funcionalidade. Nessa perspectiva, os indivíduos adotam posturas distintas de consumo, em função da necessidade de auto-apresentação diante da sociedade, o que induz a formação de um estilo próprio de consumo e a geração de status. O estabelecimento de relações contínuas e sem fascínio, volta-se a seleção e aquisição de produtos em razão da 
comodidade e necessidade de uso, atrelada a sua respectiva qualidade, durabilidade e preço, cujo falta de combinação desperta emoções negativas.

No que diz respeito ao fator relacionado à "moda", a mesma possui três Nodes: consumo comandado pelo desejo, impulso e emoção para o novo. A análise dos dados indica que a emoção para o novo é um fato preponderante, quando se trata da aquisição de um produto importado ou inovador. Essas perspectivas se vinculam diretamente a questões de irracionalidade no processo de consumo, aproximando o desejo de consumo com a busca por alternativas que lhes possibilite adquirir um produto capaz de atender aos seus anseios. Outro ponto interessante aproxima à necessidade de se acompanhar a moda, mesmo sem enxergar a utilidade prática ou os atributos do produto em seu contexto de vida e consumo.

Considerando o brand flings como um processo de aventura com as marcas, os respondentes revelaram que os fatores de "transitoriedade no relacionamento" e "motivação passageira", complementam-se quando da aquisição de uma marca, sendo a mesma mais comum no momento em que o produto consumido com maior frequência não está disponível e a necessidade de uso, mesmo que similar, é mais forte. Sob essa perspectiva, a aquisição de outros produtos permite com que o consumidor possa comparar os atributos, testá-los e definir de forma mais adequada os seus parâmetros de compra. Além disso, destaca-se que a existência de produtos similares no mercado, desperta a curiosidade dos consumidores e permite com que sejam estabelecidas relações temporárias ou longas em relação às marcas e produtos.

$\mathrm{O}$ brand flings assume ainda uma postura relacionada à "experiência vivenciada" pelos consumidores com a marca, identificada por meio de dez Nodes: sentimentos positivos, desencanto com o produto, desencanto com o serviço, interações obsessivas, ausência de brand flings, relacionamento de baixa intensidade, desencanto com a marca, conexão entre o consumidor e a marca, interações intensas e relacionamento de baixa emotividade. Todos esses fatores são expressivos, uma vez que identificam mistos de sentimentos com relação à experiência vivenciada com a marca, principalmente no que se refere à sua aceitação e às experiências que geraram algum tipo de constrangimento, sentimento negativo e uso superficial de produtos.

Considerando os achados do estudo, observa-se que o brand flings representa um tipo de relacionamento dos consumidores com marcas, conforme descrito por Alvarez e Fournier (2012), principalmente quando se trata do aspecto emocional do indivíduo, o qual é visualizado em uma fase específica da vida. Os dados apontam também o brand flings como uma tendência social (moda) determinada pela sociedade, a um ciclo de excitação (positivo) e tédio (negativo). Complementando esse entendimento, destaca-se a má experiência com a marca como um problema relacionado à qualidade, durabilidade, tamanho, aceitação de mercado (revenda) e prestação de serviços correlatos. Nesse contexto, cabe frisar que essas experiências negativas, ocorreram em alguns momentos, não com relação à marca em si, mas quanto aos fatores de entrega, acessibilidade e disponibilidade de produtos. 


\section{CONSIDERAÇÕES FINAIS E RECOMENDAÇÕES}

A pesquisa se propôs a estudar o fenômeno brand flings como um tipo de relacionamento com as marcas. $\mathrm{O}$ estudo fundamenta-se nas discussões abordadas nos estudos de Fournier (1998) e Alvarez e Fournier (2012), quanto às relações passageiras dos indivíduos com as marcas. Para tanto, fez-se uso de um roteiro de entrevistas semiestruturada, contemplando elementos sobre relações passageiras de consumo. Com relação a isso, percebe-se que existem quatro eixos para a determinação do relacionamento do tipo brand flings: relacionamento emocional com a marca, interações intensas e obsessivas, superficialidade no processo de tomada de decisão e conexão do consumidor com a marca.

Nesse contexto, considerando os resultados da pesquisa, verifica-se que os procedimentos para análise dos dados perpassaram pela: (a) pré-análise; (b) exploração do material; e (c) tratamento dos resultados, inferência e interpretação. $\mathrm{Na}$ etapa de pré-análise, foram identificadas a frequência de palavras citadas nas entrevistas, com destaque para "marcas", "marca", "relação", como resultado do envolvimento dos participantes com as marcas citadas. Além disso, destacou-se a freqüência na adoção de termos relacionados à "qualidade", "preço" e "tempo", que se configuram como fatores que influenciam o processo de escolha da marca.

Na etapa de exploração do material, realizou-se a codificação da entrevista com a finalidade de categorizar as falas dos respondentes, de acordo com o que preceitua as orientações de Alvarez e Fournier (2012), quanto ao brand flings. Nesse sentido, foram identificados 92 códigos de análise de conteúdo, empregados em 758 citações ou trechos textuais, o que representou um índice de 8,24 trechos de frases ou frases por código. Dessa análise foram identificadas quatro grandes áreas (momento de vida, moda, motivação passageira e experiência vivenciada) com seus respectivos códigos (famílias), que corresponderam ao método dedutivo de análise, com base nos conceitos definidos pelo brand flings.

Em seguida, a etapa de tratamento dos resultados, inferência e interpretação, foram analisadas quanto aos respectivos códigos (famílias), em virtude do relacionamento do tipo brand flings. A esse respeito, constatou-se que a aquisição ou uso das marcas escolhidas pelos entrevistados, permanecem envolvidos com o aspecto emocional do indivíduo, acarretando um misto de sentimentos, que norteiam o relacionamento positivo ou negativo, associado à aquisição ou uso da marca.

Considerando os fatores enumerados, sugerem-se que sejam realizados experimentos que possibilitem explorar os aspectos inerentes as relações passageiras com marcas de produtos similares, brand flings. Também seria interessante fazer um estudo longitudinal com jovens que se encontram em processo de formação e que dispõem de recursos limitados, como os adolescentes. Recomenda-se ainda, o desenvolvimento de estudos com mães de primeira viagem, que precisam 
experimentar e definir o tipo de produto de higiene pessoal e de uso diário, mais adequado para o seu bebê.

\section{REFERÊNCIAS}

AAKER, J., FOURNIER S.; BRASEL, S.A. When good brands do bad. Journal of Consumer Research, vol. 31, jun. 2004, pp. 01-16.

AGGARWAL, P. The Effects of Brand Relationship Norms on consumer Attitudes and Behavior. Journal of Consumer Research. vol. 31, jun. 2004, pp. 87-101.

AHLUWALIA, R.; KAIKATI, A.M. Traveling the paths to brand loyalty. In: LOKEN, B.; AHLUWALIA, R.; HOUSTON, M.J. Brands and brand management: contemporary research perspectives. Routledge: New York, 2010, pp. 63-90.

ALVAREZ, C.; FOURNIER, S. Brand flings: when great brand relationships are not made to last. In> FOURNIER, S.; BREZEALE, M.; FETSCHERIN, M. Consumerbrand relationships: theory and practice. New York: Routledge, 2012, pp. 74-96.

BARDIN, L. Análise de conteúdo. Lisboa: Edições 70, 1977.

BAUMAN, Z. Consuming Life. Journal of Consumer Culture, vol. 1, n. 1, mar. 2001, pp. 9-29.

BLACKSTON, M. Observations: building brand equity by managing the brand's relationship. Journal of Advertising Research, vol. 40, n. 6, nov./dec. 2000, pp. 101105.

BROWN, S. Postmodern marketing? European Journal of Marketing, vol. 27, n. 4, set./dec. 1993, pp. 19-34.

ESCALAS, J.E.; BETTMAN, J.R. Self-Construal, Reference Groups, and Brand Meaning. Journal of Consumer Research. vol. 32, dec. 2005, pp. 378-389.

FOURNIER, S. Consumers and their brands: developing relationship theory in consumer research. Journal of Consumer Research, vol. 24, n. 4, mar. 1998, pp. 343353.

FOURNIER, S. Lessons learned about consumers' relationshoips with their brands. In: MACINNIS, D.; PARK, C.W.; PRIESTER, J.R. Handbook of brand relashionships. M.E.Sharpe: New York, 2009, pp. 5-23. 
FOURNIER, S.; ALVAREZ, C. Relating badly to brands. Journal of Consumer Psychology, vol. 23, n. 2, jan. 2013, pp. 253-264.

GIFFORD JR, D. Moving beyond loyalty. Harvard Business Review, vol. 75, n. 2, mar./abr. 1997, pp. 9-10.

GIL-JUÁREZ, A. Consumption as an Emotional Social Control Device. Theory Psychology, vol. 19, n. 06, dez. 2009, pp. 837-858.

HEDING, T.; KNUDTZEN, C.F.; BJERRE, M. Brand Management: Research, theory and practice. New York: Routledge, 2009.

ILLOUZ, E. Emotions, Imagination and Consumption: A new research agenda. Journal of Consumer Culture, vol. 9, n. 3, nov. 2009, pp. 377-413.

MACIEL, C. O.; WEYMER, A. S. Q.; AUGUSTO, P. O. M. Identificando os condicionantes socialmente construídos (Enacted) das práticas estratégicas em ambientes altamente institucionalizados. Revista RAC, vol. 16, n. 1, jan./fev. 2012, pp. 79-97.

MACINNIS, D. J.; PARK, C.W.; PRIESTER, J. R. (Eds.). Handbook of brand relationships. New York: M.E. Sharpe, 2009.

MARTINS, G. A.; THEÓPHILO, C. R. Metodologia da investigação científica para as ciências sociais aplicadas. 2. ed. São Paulo: Atlas, 2009.

McCRACKEN, G. Who is the Celebrity Endorser? Cultural Foundations of the Endorsement Process. Journal of Consumer Research, vol. 16, n. 3, dec. 1989, pp. 310-321.

MILLER, F., FOURNIER, S.; ALLEN, C. Exploring relationship analogues in the brand space. In: FOURNIER, S.; BREAZEALE, M.; FETSCHERIN, M. (eds.). Consumer-brand relationships: theory and practice. New York: Routledge, 2012, pp. 30-56.

PARK, J.W; KIM, H. KIM, J. Acceptance of brand extensions: interactive influences of product category similarity, typicality of claimed benefits, and brand relationship quality. Advances in Consumer Research. Valdosta: Associations of Consumer Research, vol. 29, 2002, pp. 190-198. 
ROSA, M. V. F. P. C.; ARNOLDI, M. A. G. C. A entrevista na pesquisa qualitativa: mecanismo para validação dos resultados. Belo Horizonte: Autêntica, 2006.

SMITHEE, A. Kotler is dead! European Journal of Marketing, vol. 31, n. 3-4, 1997, pp. 317-325.

STERNBERG, R. J. A triangular theory of love. Psychological Review, vol. 93, n. 2, abr. 1986, pp.119-135.

SWAMINATHAN, V.; DOMMER, S. L. When is our connection to brand like our connection to people? Differentiating between consumer-brand relationships and interpersonal relationships. In: FOURNIER, S.; BREAZEALE, M.; FETSCHERIN, M. (eds.). Consumer-brand relationships: theory and practice. New York: Routledge, 2012, pp. 15-29.

THOMSON, M.; MACINNIS, D.J.; PARK, C.W. The ties that bind: measuring the strength of consumers'emotional attachments to brands. Journal of consumer psychology, vol. 15, n.1, 2005, pp. 77-91.

WINNICOTT, D.W. Transitional Objects and Transitional Phenomena: A Study of the First Not-Me Possession. International Journal of Psycho-Analysis, vol. 34, 1953, pp. 89-97.

YIN, R. K. Estudo de caso: planejamento e métodos. 4. ed. Porto Alegre: Bookman, 2010. 